\title{
Expression of KIT (CD117) in Neoplasms of the Head and Neck: An Ancillary Marker for Adenoid Cystic Carcinoma
}

\author{
M. Mino, M.D., B.Z. Pilch, M.D., W.C. Faquin, M.D., Ph.D. \\ Department of Pathology, Massachusetts General Hospital, Harvard Medical School, \\ Boston, Massachusetts
}

\begin{abstract}
Adenoid cystic carcinoma is an indolent salivary gland malignancy that is associated with a poor long-term prognosis. The distinction of adenoid cystic carcinoma from other head and neck neoplasms can occasionally be problematic, particularly in small biopsies. Recent studies suggest that KIT (CD117) might be useful as an ancillary marker for adenoid cystic carcinoma; however, the expression of KIT in other benign and malignant head and neck neoplasms, including those that might mimic adenoid cystic carcinoma, has not been well studied. Here we use two different antibodies against KIT to evaluate its expression in a series of 66 adenoid cystic carcinomas compared with its expression in 98 other neoplasms of the head and neck. Overall, 94\% ( $n=62)$ of adenoid cystic carcinomas from various anatomic sites and of various histologic subtypes were positive for at least one of the KIT antibodies, and $77 \%(n=50)$ of adenoid cystic carcinoma cases were positive for both antibodies. This contrasted with only $8 \%(n=8)$ of other head and neck neoplasms that were positive for both KIT antibodies $(P<.001)$. It was of note that certain neoplasms, including pleomorphic adenoma, basal cell adenoma, polymorphous low-grade adenocarcinoma, and basal cell carcinoma, that can show histologic overlap with adenoid cystic carcinoma had significantly less KIT immunoreactivity than did adenoid cystic carcinoma $(P<.001)$. In contrast, KIT expression did not reliably distinguish adenoid cystic carcinoma from basal cell adenocarcinoma and basaloid squamous carcinoma $(P>$ .05). The overall sensitivity of the two KIT antibod-
\end{abstract}

\footnotetext{
Copyright () 2003 by The United States and Canadian Academy of Pathology, Inc.

VOL. 16, NO. 12, P. 1224, 2003 Printed in the U.S.A.

Date of acceptance: August 15, 2003.

Portions of this work were presented at the United States and Canadian Academy of Pathology, Chicago, IL, 2002.

Address reprint requests to: W.C. Faquin, M.D., Ph.D., Department of Pathology, Warren 219, Massachusetts General Hospital, 55 Fruit Street, Boston, MA 02114; fax: 617-573-3389; e-mail: wfaquin@partners.org.

DOI: 10.1097/01.MP.0000096046.42833.C7
}

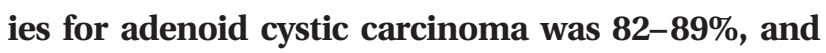
the specificity was $87-88 \%$. The findings in this study support the potential use of KIT immunoexpression for distinguishing adenoid cystic carcinoma from many other benign and malignant head and neck neoplasms.

KEY WORDS: Adenoid cystic carcinoma, CD117, Head and neck neoplasms, KIT, Salivary gland.

Mod Pathol 2003;16(12):1224-1231

c-kit maps to the long arm of chromosome 4 and encodes a transmembrane receptor-type tyrosine kinase, KIT, that is structurally and functionally related to platelet-derived growth factor and colonystimulating factor-1 receptors (1-3). After binding to its ligand, alternatively known as stem cell factor, mast cell growth factor, or steel factor, KIT begins a signaling cascade that contributes to the regulation of cell growth and differentiation $(4,5)$. KIT expression previously has been documented in a wide variety of human malignancies including mastocytosis/mast cell leukemia (6-8), germ cell tumor (9-13), small cell lung carcinoma (8), gastrointestinal stromal tumor $(14,15)$, acute myelogenous leukemia (16-18), ovarian carcinoma $(8,19)$, endometrial carcinoma $(8,20)$, breast carcinoma $(21,22)$, and angiosarcoma (23).

Adenoid cystic carcinoma is a malignant salivary gland neoplasm characterized by an indolent growth pattern with marked neurotropism, late onset of metastasis, and overall poor long-term survival (24-33). Because of its aggressive behavior, it is important to distinguish adenoid cystic carcinoma from other benign and malignant neoplasms of the head and neck, including those that can mimic adenoid cystic carcinoma in small biopsies. Recent studies indicate that KIT (CD117) is expressed in some adenoid cystic carcinomas (3436), raising the possibility that KIT might be useful as an ancillary marker for this tumor. To investigate this, we studied KIT expression in a series of 98 
benign and malignant tumors of the head and neck, including those that can show histologic overlap with adenoid cystic carcinoma, such as pleomorphic adenoma, polymorphous low-grade adenocarcinoma, basal cell adenoma and adenocarcinoma, basal cell carcinoma, and basaloid squamous carcinoma.

In tumors other than gastrointestinal stromal tumors, Miettinen (37) and Hornick and Fletcher (38) have recently suggested that apparent discrepancies in the specificity of KIT immunostaining may reflect differences in the polyclonal antibodies used and epitope retrieval methods applied. Therefore, in the present study, we use antibodies against two different protein domains of KIT. To the best of our knowledge, this study represents the largest series of head and neck tumors examined for KIT immunoexpression as well as the first to study KIT expression in both benign and malignant tumors, including many that can mimic adenoid cystic carcinoma.

\section{MATERIALS AND METHODS}

\section{Case Selection}

Sixty-six adenoid cystic carcinomas from the head and neck $(n=53)$, trachea $(n=11)$, and breast $(n=2)$, as well as 98 other neoplasms of the head and neck (pleomorphic adenoma, $n=16$; basal cell adenoma, $n=6$; basal cell adenocarcinoma, $n=5$; basal cell carcinoma, $n=11$; polymorphous low-grade adenocarcinoma, $n=8$; adenosquamous carcinoma, $n=4$; basaloid squamous carcinoma, $n=6$; sebaceous carcinoma, $n=6$; mucoepidermoid carcinoma, $n=9$; salivary duct carcinoma, $n=4$; acinic cell carcinoma, $n=8$; oncocytoma, $n=5$; Warthin's tumor, $n=10$ ) were selected from the 1983-2002 archival pathology files of the Massachusetts General Hospital, based on the availability of glass slides and paraffinembedded material.

\section{Immunohistochemistry and Analysis}

Immunohistochemical studies were performed on $4-\mu \mathrm{m}$-thick, formalin-fixed, paraffin-embedded tissue sections using a modified avidin-biotinperoxidase complex detection method (Vector Labs $\mathrm{ABC}$ technique) with antigen retrieval and overnight incubation. Heat-induced epitope retrieval was performed by heating tissue sections in a buffered citric acid solution (Citra, from BioGenex, San Ramon, CA) for 3 minutes using a Borg Decloaker electric pressure cooker (Biocare Medical Inc., Walnut Creek, CA). Two different antibodies were used for detecting KIT expression: H300, a polyclonal antibody to the amino terminus of the human KIT
(1:65 dilution; Santa Cruz Biotechnology, Santa Cruz, CA) and A4502, a polyclonal antibody to the carboxy terminus of the human KIT (1:100 dilution; DAKO Corp., Carpinteria, CA). Tissue mast cells and separately stained sections of gastrointestinal stromal tumor were used as positive controls. Negative controls included sections stained with nonimmune serum without primary antibody as well as normal salivary gland tissue that was present in many cases and that served as a baseline internal negative control in this study.

Immunohistochemical reactivity was analyzed by two observers (MM, WCF). Both cytoplasmic and membrane staining were assessed. To maximize antibody specificity by minimizing the influence of nonspecific and focal staining in normal tissue and in some tumors, the following criteria were used: cases were considered "negative" when $<10 \%$ of cells showed cytoplasmic staining, "positive" when $\geq 10 \%$ of tumor cells showed cytoplasmic staining with an intensity greater than that present within background salivary gland tissue (35), and "strongly positive" when both cytoplasmic and membrane staining were present in $\geq 10 \%$ of cells. Membraneonly staining was not observed in any of the examined cases.

STATA software (STATA Corporation, College Station, TX; Release 6) was used for statistical analysis of the immunohistochemical data. The $\chi^{2}$ test was used to evaluate the difference in KIT staining between adenoid cystic carcinomas and other head and neck neoplasms. A $P$ value of $<.05$ was considered significant.

\section{RESULTS}

\section{Clinicopathologic Data}

The 66 cases of adenoid cystic carcinoma included in this study consisted of 35 men and 31 women, with an average age of 52 years (range: 13-81 y). Tumor sites included the parotid gland ( $n=11)$, submandibular gland $(n=4)$, lacrimal gland/orbit $(n=6)$, minor salivary glands of the oral cavity $(n=12)$, maxillary and ethmoid sinuses $(n=11)$, nasal cavity $(n=7)$, ear canal $(n=2)$, tracheobronchial tree $(n=11)$, and breast $(n=2)$. Among the cases of adenoid cystic carcinoma, histologic subtypes included cribriform $(n=40)$, tubular $(n=9)$, solid $(n=8)$, and mixed $(n=9)$.

\section{KIT Immunoreactivity in Adjacent Nonneoplastic Tissue}

Strong KIT expression with distinctive cytoplasmic membrane staining was noted within tissueassociated mast cells. Luminal epithelia of the intercalated ducts and striated ducts of normal 
salivary glands and basal cells of skin showed variable weak immunoreactivity for KIT, as has also been reported by others (35); however, this immunoreactivity was below the threshold that was considered "positive" within this study. Overall, H300 immunostaining demonstrated a higher nonspecific background than the A4502 antibody.

\section{Immunostaining of Adenoid Cystic Carcinomas}

Eighty-two percent $(n=54)$ and $89 \%(n=58)$ of adenoid cystic carcinomas were positive for KIT using H300 and A4502, respectively (Table 1; Fig. 1). Overall, 94\% ( $n=62$ ) of adenoid cystic carcinomas were positive for at least one of the two antibodies, and $77 \%(n=50)$ of cases were positive for both antibodies. There was no statistically significant difference in the immunoreactivity among adenoid cystic carcinomas from different primary anatomic sites. Among histologic subtypes of adenoid cystic carcinoma, $100 \%$ of both tubular $(n=9)$ and solid ( $n=8$ ) subtypes were positive with the two KIT antibodies, whereas only $73 \%$ and $82 \%$ of the cribriform subtype were positive with H300 and A4502, respectively. Seven cases $(88 \%)$ of the mixed subtype were positive with $\mathrm{H} 300$ and 8 cases (100\%) with A4502. Both cytoplasmic and membrane staining were present with $\mathrm{H} 300$ and A4502, respectively, in $37 \%$ and $61 \%$ of the cribriform subtype, $50 \%$ and $75 \%$ of the solid subtype, $89 \%$ and $78 \%$ of the tubular subtype, and $74 \%$ and $100 \%$ of the mixed subtype.

A distinct immunohistologic pattern of staining was noted among the tubular, cribriform, and mixed subtypes of adenoid cystic carcinoma in cases where the inner epithelial cells, but not the outer myoepithelial cells, showed strong immunoreactivity. This pattern was particularly pro- nounced in the tubular subtype (Fig. 1D). In contrast, in the solid subtype of adenoid cystic carcinoma, tumor cells exhibited immunohistochemical evidence of KIT expression in a diffuse pattern (Fig. 1H).

\section{Other Head and Neck Neoplasms}

In contrast to adenoid cystic carcinoma, the number of KIT-immunopositive cases among the 98 other salivary gland and head and neck neoplasms included in this study were $12 \%$ and $13 \%$ ( $n=12$ ) with H300 and A4502, respectively, and $16 \%(n=16)$ with at least one of the two antibodies (Table 1$)$. Only $8 \%(n=8)$ of these cases showed positive KIT expression using both KIT antibodies. As an ancillary marker for adenoid cystic carcinoma, the H300 antibody had a sensitivity of $82 \%$ and a specificity of $88 \%$ compared with A4502, which had a slightly higher sensitivity (89\%) and equivalent specificity (87\%).

Among tumors that might be considered in the differential diagnosis of adenoid cystic carcinoma, significant differences were seen in KIT expression for adenoid cystic carcinoma versus pleomorphic adenoma, basal cell adenoma, polymorphous lowgrade adenocarcinoma, and basal cell carcinoma, with $0-25 \%$ staining with either antibody $(P<.001)$ and only $0-5 \%$ staining with both antibodies. In contrast, $60 \%$ of basal cell adenocarcinomas and $50 \%$ of basaloid squamous carcinomas showed KIT expression using at least one of the two antibodies (Table 1, Fig. 2). Positive cases of basaloid squamous carcinoma had a strong diffuse pattern of staining, whereas some positive cases of basal cell adenocarcinoma had a heterogeneous pattern reminiscent of the tubular and mixed subtypes of adenoid cystic carcinoma. Other head and neck neo-

TABLE 1. KIT Expression in Head and Neck Neoplasms

\begin{tabular}{|c|c|c|c|c|c|}
\hline \multirow{3}{*}{ Tumors (N) } & \multicolumn{5}{|c|}{ Antibodies } \\
\hline & \multicolumn{2}{|r|}{ Н300 } & \multicolumn{2}{|r|}{ A4502 } & \multirow{2}{*}{$\frac{\text { KIT }}{\text { Positive }^{* * *} \%(\mathrm{~N})}$} \\
\hline & Positive* \% (N) & Strongly positive ${ }^{* *} \%(\mathrm{~N})$ & Positive* \% (N) & Strongly positive** \% (N) & \\
\hline Adenoid cystic carcinoma (66) & $30(20)$ & $52(34)$ & $18(12)$ & $71(46)$ & $94(62)$ \\
\hline Pleomorphic adenoma (16) & $6(1)$ & $6(1)$ & $6(1)$ & $6(1)$ & $19(3)$ \\
\hline Basal cell adenoma (6) & $0(0)$ & $17(1)$ & $17(1)$ & $0(0)$ & $17(1)$ \\
\hline Basal cell adenocarcinoma (5) & $20(1)$ & $20(1)$ & $40(2)$ & $20(1)$ & $60(3)$ \\
\hline Basal cell carcinoma (11) & $0(0)$ & $0(0)$ & $0(0)$ & $0(0)$ & $0(0)$ \\
\hline $\operatorname{PLGC}^{a}(8)$ & $0(0)$ & $0(0)$ & $25(2)$ & $0(0)$ & $25(2)$ \\
\hline Adenosq. carcinoma $^{b}(4)$ & $0(0)$ & $0(0)$ & $0(0)$ & $0(0)$ & $0(0)$ \\
\hline Basaloid sq. carcinoma ${ }^{c}(6)$ & $17(1)$ & $33(2)$ & $17(1)$ & $33(2)$ & $50(3)$ \\
\hline Sebaceous carcinoma $(6)$ & $17(1)$ & $0(0)$ & $17(1)$ & $0(0)$ & $17(1)$ \\
\hline Mucoepidermoid carcinoma (9) & $11(1)$ & $0(0)$ & $0(0)$ & $0(0)$ & $11(1)$ \\
\hline Salivary duct carcinoma (4) & $25(1)$ & $0(0)$ & $0(0)$ & $0(0)$ & $25(1)$ \\
\hline Acinic cell carcinoma (8) & $0(0)$ & $13(1)$ & $0(0)$ & $0(0)$ & $13(1)$ \\
\hline Oncocytoma (5) & $0(0)$ & $0(0)$ & $0(0)$ & $0(0)$ & $0(0)$ \\
\hline Warthin's tumor (10) & $0(0)$ & $0(0)$ & $0(0)$ & $0(0)$ & $0(0)$ \\
\hline Total of other tumors (98) & $6(6)$ & $6(6)$ & $8(8)$ & $4(4)$ & $16(16)$ \\
\hline
\end{tabular}

* Cytoplasmic staining only; ${ }^{* *}$ cytoplasmic and membrane staining; ${ }^{* * *}$ positive staining with at least one of the two antibodies.

${ }^{a}$ Polymorphous low grade carcinoma; ${ }^{b}$ adenosquamous carcinoma; ${ }^{c}$ basaloid squamous carcinoma. 

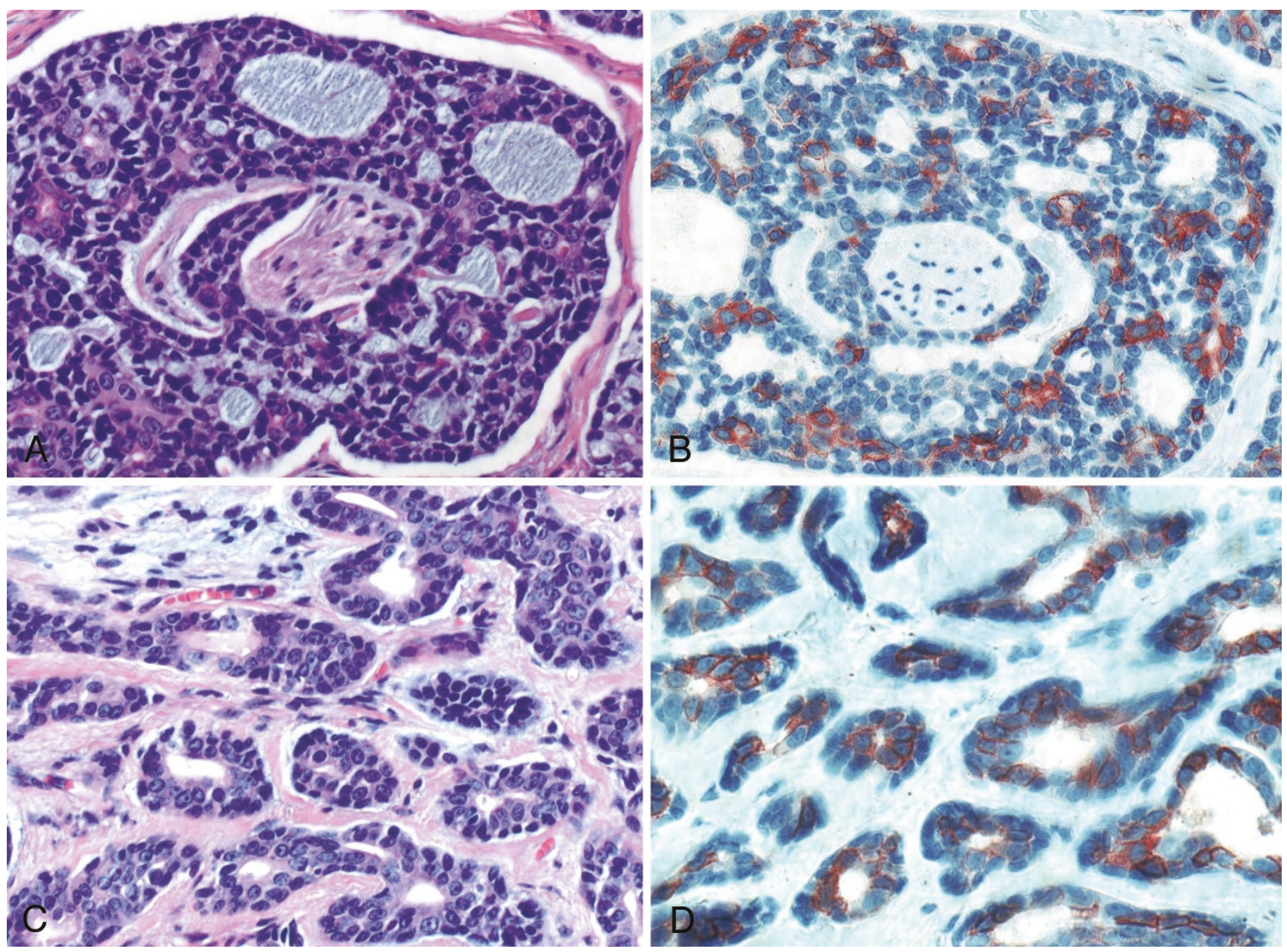

FIGURE 1a. KIT immunohistochemical reactivity in subtypes of adenoid cystic carcinoma. A, cribriform subtype exhibiting perineural invasion and (B) many strongly positive epithelial cells; C, tubular subtype showing (D) a distinct immunohistochemical pattern of inner epithelial cell positivity, whereas peripheral myoepithelial cells are negative (H\&E and immunohistochemical reaction; all panels, original magnification $400 \times$ ).

plasms examined where KIT expression was significantly less than adenoid cystic carcinoma included mucoepidermoid carcinoma, salivary duct carcinoma, acinic cell carcinoma, oncocytoma, Warthin's tumor, adenosquamous carcinoma, and sebaceous carcinoma (Table 1).

\section{DISCUSSION}

Because of its poor long-term prognosis and limited clinical treatment options, adenoid cystic carcinoma is important to distinguish histologically from other tumors of the head and neck. Studies from other groups have indicated that adenoid cystic carcinomas express KIT that is immunohistochemically detectable (34-36), raising the possibility that antibodies against KIT could function diagnostically as an ancillary marker for adenoid cystic carcinoma. This could be particularly important in small biopsies, where distinction between adenoid cystic carcinoma and certain other benign and malignant head and neck neoplasms may be challenging. Our study, representing one of the largest series of head and neck neoplasms examined for KIT immunoreactivity and the first to examine KIT expression in both benign and malignant tumors, including many that can histologically mimic adenoid cystic carcinoma, supports the potential use of KIT as an ancillary marker for adenoid cystic carcinoma. Among tumors that in some cases can be difficult to distinguish from adenoid cystic carcinoma, immunohistochemical staining for expression of KIT is potentially useful for distinguishing adenoid cystic carcinoma from pleomorphic adenoma, basal cell adenoma, polymorphous lowgrade adenocarcinoma, and basal cell carcinoma. Although less frequently considered in the differential diagnosis with adenoid cystic carcinoma, a variety of other salivary gland and head and neck neoplasms was also studied, not only to determine the specificity of KIT immunoreactivity for adenoid cystic carcinoma versus other head and neck tumors but also to explore the extent to which KIT expression might be potentially involved in the carcinogenesis of other head and neck neoplasms. The latter is important because KIT expression in any 


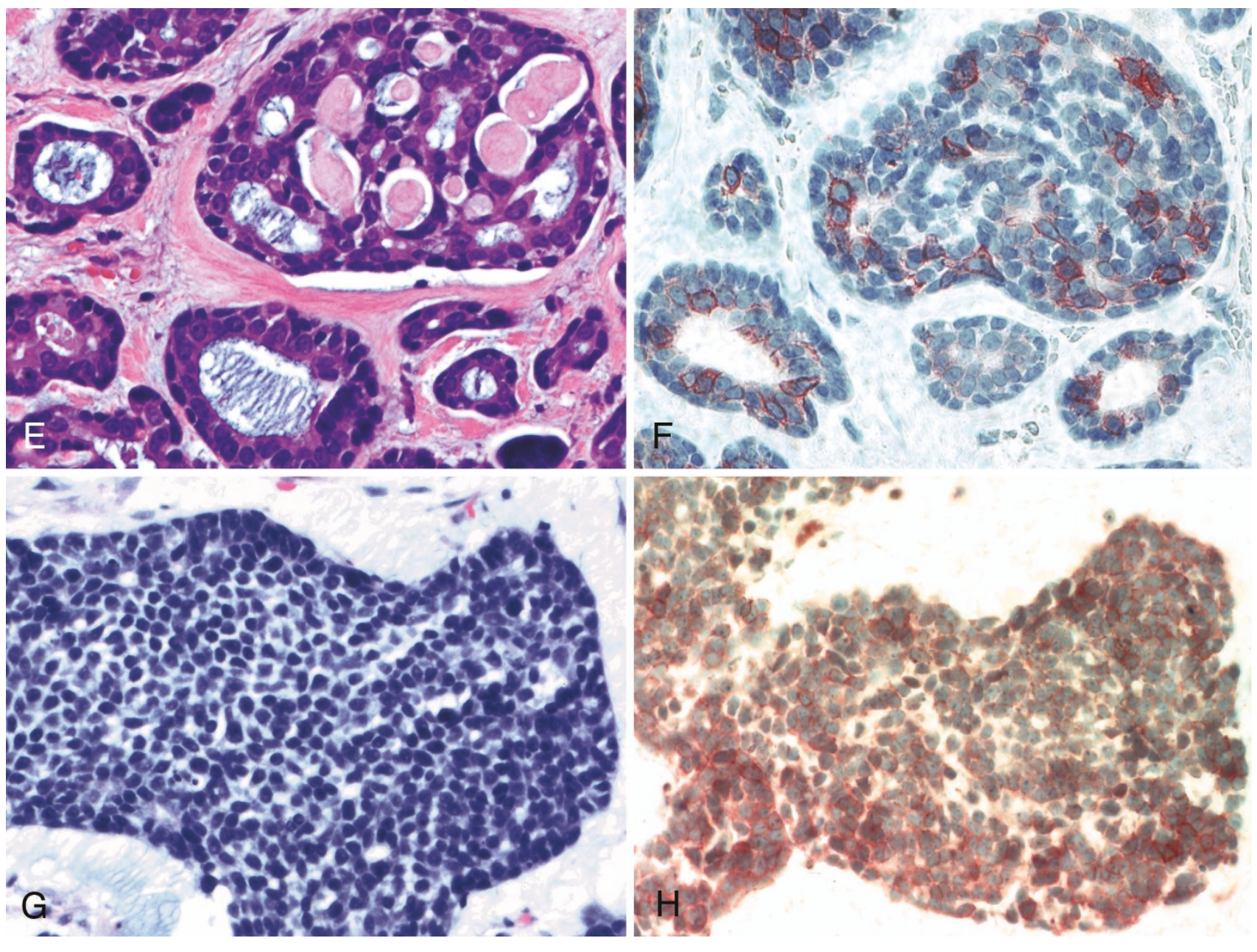

FIGURE 1b. KIT immunohistochemical reactivity in subtypes of adenoid cystic carcinoma. E, mixed cribriform and tubular subtype showing (F) many strongly positive epithelial cells; G, solid subtype demonstrating $(\mathbf{H})$ a diffuse immunohistochemical staining pattern. (H\&E and immunohistochemical reaction; all panels, original magnification $400 \times$ ).

tumor raises the possibility of developing treatment strategies using inhibitors of tyrosine kinase activity.

Although KIT expression was not identified in most basaloid as well as other salivary gland and head and neck neoplasms in our study, it was present in up to $60 \%$ of basal cell adenocarcinomas and $50 \%$ of basaloid squamous carcinomas. As with adenoid cystic carcinoma, this finding suggests that KIT expression might play a biologic role in these tumors. Because basal cell adenocarcinoma and basaloid squamous carcinoma are very rare head and neck tumors, only small numbers were available for study, and larger series of these particular neoplasms would be useful to confirm the extent of KIT expression in these tumors. Of these two neoplasms, basal cell adenocarcinoma is a histologically lower grade malignancy that would be potentially more challenging to distinguish from adenoid cystic carcinoma than basaloid squamous carcinoma; the latter exhibits high-grade malignant features that are less commonly seen in adenoid cystic carcinoma.
KIT immunoexpression has been reported in a variety of mesenchymal, epithelial, and hematopoietic tumors; however, some discrepancies in detectable KIT expression exist between different studies, possibly reflecting differences in the polyclonal antibodies used and in the epitope retrieval modalities applied (37-39). For this reason, our study was performed using two different KIT antibodies, one to the amino terminus and one against the carboxy terminus of human KIT. Although higher background staining was present with the amino terminus antibody (H300), both antibodies had similar high sensitivities and specificities for the detection of adenoid cystic carcinoma. Our findings indicate that the use of two separate antibodies, together with strict criteria for interpreting a result as positive, significantly improves the specificity of the antibody results. For example, pleomorphic adenoma, a potential benign mimic of adenoid cystic carcinoma, was positive for at least one KIT antibody in 3 of 16 cases examined but was positive for both antibodies in only 1 of 16 cases. Strict criteria for a positive result are necessary be- 

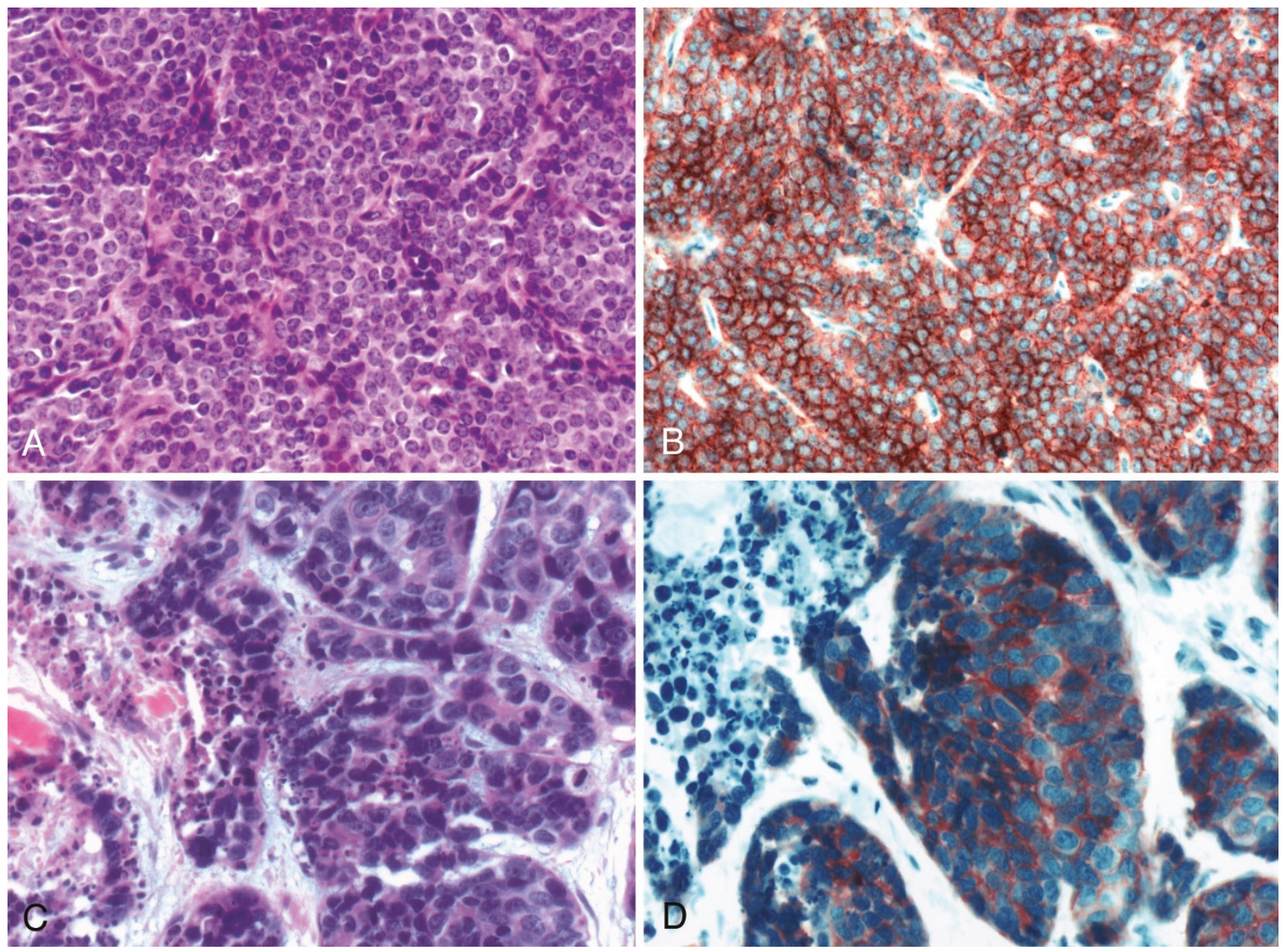

FIGURE 2. A, basal cell adenocarcinoma showing low-grade histologic features and (B) strong diffuse staining for KIT; C, basaloid squamous carcinoma demonstrating high-grade cytologic atypia with associated necrosis and (D) strong diffuse staining for KIT. (H\&E and immunohistochemical reaction; all panels, original magnification $400 \times$ ).

cause focal KIT expression was occasionally detected in some tumors; however, strong immunoreactivity in $>10 \%$ of the tumor cells with each of two different antibodies was characteristic of adenoid cystic carcinoma, and to a lesser extent, of basal cell adenocarcinoma and basaloid squamous carcinoma.

Although no significant differences in KIT expression were found in adenoid cystic carcinomas from different anatomic sites, there were differences in KIT expression for adenoid cystic carcinomas of different histologic subtypes. KIT expression was lowest among the cribriform subtype and highest among the tubular and solid subtypes of adenoid cystic carcinoma, the solid subtype being one of the most diagnostically challenging forms. Thus, although positive KIT expression is characteristic of adenoid cystic carcinoma, a negative KIT immunostaining pattern in a tumor with a cribriform architecture should be interpreted with caution, especially in the setting of a small biopsy. Fortunately, the cribriform subtype of adenoid cystic carcinoma presents the least diagnostic challenge.
The pattern of immunostaining also varied between the different histologic subtypes of adenoid cystic carcinoma, as has also been recognized by other investigators $(34,36)$. Although the solid subtype of adenoid cystic carcinoma showed a mostly diffuse pattern of immunoreactivity, the tubular and cribriform subtypes demonstrated KIT expression primarily within the luminal epithelial cell layer. It has been suggested that this difference in the pattern of KIT expression within the solid subtype compared with the tubular and cribriform subtypes may reflect a loss of cellular heterogeneity in the former, with differentiation primarily along the line of the luminal epithelial cell (36). It is tempting to speculate that this cellular difference might be related to the generally more aggressive behavior of the solid subtype of adenoid cystic carcinoma (24, $27,30,40-45)$. Similar to the solid subtype of adenoid cystic carcinoma, some cases of basaloid squamous carcinoma also showed a diffuse staining pattern that included both cytoplasmic and membrane staining. In contrast, the pattern in some positive cases of basal cell adenocarcinoma 
showed strong staining of only the scattered epithelial cells but not of the myoepithelial cells, reminiscent of the pattern seen in the cribriform and tubular subtypes of adenoid cystic carcinoma.

The contribution of the $c$-kit pathway to cell proliferation and carcinogenesis in adenoid cystic carcinomas is unclear, especially because the presence of a specific $c$-kit mutation $(27,46-50)$ has yet to be detected within the small number of adenoid cystic carcinomas studied $(11,12)$. A possible autocrine and/or paracrine stimulation of the receptor by its ligand, stem cell factor, proposed for KIT activation in other tumors such as small cell carcinoma of the lung, ovarian carcinoma, breast cancer, melanoma, and tumor-derived cell lines, might also apply to adenoid cystic carcinomas (21, 46-50). However, Oliveira et al. (51) have recently demonstrated that KIT was expressed but not phosphorylated in a series of four adenoid cystic carcinomas examined and concluded that KIT expression is unlikely to have a direct oncogenic function in adenoid cystic carcinomas, in contrast to its role in gastrointestinal stromal tumors. To elucidate the biologic role of $c$-kit in adenoid cystic carcinomas as well as a potential role in basaloid squamous carcinoma and basal cell adenocarcinoma, further molecular studies that include larger numbers of cases will be needed.

In summary, the expression of KIT within a majority of adenoid cystic carcinomas and within few other head and neck neoplasms suggests that antibodies to KIT are potentially useful in the diagnostic evaluation of adenoid cystic carcinoma, especially when applied using strict criteria. Although most mimics of adenoid cystic carcinoma including pleomorphic adenoma, basal cell adenoma, polymorphous low-grade adenocarcinoma, and basal cell carcinoma show little expression of KIT, some increased KIT expression was observed in basal cell adenocarcinoma and basaloid squamous carcinoma. Thus, caution is warranted in using KIT expression to distinguish these latter two carcinomas from adenoid cystic carcinoma, especially in small biopsies.

Acknowledgment: The authors thank Quin Vo for her technical assistance in this study.

\section{REFERENCES}

1. Yarden Y, Kuang WJ, Yang-Feng T, Coussens L, Munemitsu S, Dull TJ, et al. Human proto-oncogene c-kit: a new cell surface receptor tyrosine kinase for an unidentified ligand. EMBO J 1987;6:3341-51.

2. Vandenbark GR, deCastro CM, Taylor H, Dew-Knight S, Kaufman RE. Cloning and structural analysis of the human c-kit gene. Oncogene 1992;7:1259-66.
3. Vliagoftis H, Worobec AS, Metcalfe DD. The protooncogene c-kit and c-kit ligand in human disease. J Allergy Clin Immunol 1997;100:435-40.

4. Funasaka Y, Boulton T, Cobb M, Yarden Y, Fan B, Lyman SD, et al. c-Kit-kinase induces a cascade of protein tyrosine phosphorylation in normal human melanocytes in response to mast cell growth factor and stimulates mitogen-activated protein kinase but is down-regulated in melanomas. Mol Biol Cell 1992;3:197-209.

5. Brizzi MF, Zini MG, Aronica MG, Blechman JM, Yarden Y, Pegoraro L. Convergence of signaling by interleukin-3, granulocyte-macrophage colony-stimulating factor, and mast cell growth factor on JAK2 tyrosine kinase. J Biol Chem 1994;269:31680-4.

6. Longley BJ, Jr, Metcalfe DD, Tharp M, Wang X, Tyrrell L, Lu $\mathrm{SZ}$, et al. Activating and dominant inactivating c-KIT catalytic domain mutations in distinct clinical forms of human mastocytosis. Proc Natl Acad Sci U S A 1999;96:1609-14.

7. Natkunam Y, Rouse RV. Utility of paraffin section immunohistochemistry for C-KIT (CD117) in the differential diagnosis of systemic mast cell disease involving the bone marrow. Am J Surg Pathol 2000;24:81-91.

8. Arber DA, Tamayo R, Weiss LM. Paraffin section detection of the c-kit gene product (CD117) in human tissues: value in the diagnosis of mast cell disorders. Hum Pathol 1998;29: 498-504.

9. Tian Q, Frierson HF Jr, Krystal GW, Moskaluk CA. Activating c-kit gene mutations in human germ cell tumors. Am J Pathol 1999;154:1643-7.

10. Bokemeyer C, Kuczyk MA, Dunn T, Serth J, Hartmann K, Jonasson J, et al. Expression of stem-cell factor and its receptor c-kit protein in normal testicular tissue and malignant germ-cell tumours. J Cancer Res Clin Oncol 1996;122: 301-6.

11. Izquierdo MA, Van der Valk P, Van Ark-Otte J, Rubio G, Germa-Lluch JR, Ueda R, et al. Differential expression of the c-kit proto-oncogene in germ cell tumours. J Pathol 1995; 177:253-8.

12. Rajpert-De Meyts E, Skakkebaek NE. Expression of the c-kit protein product in carcinoma-in-situ and invasive testicular germ cell tumours. Int J Androl 1994;17:85-92.

13. Kraggerud SM, Berner A, Bryne M, Pettersen EO, Fossa SD. Spermatocytic seminoma as compared to classical seminoma: an immunohistochemical and DNA flow cytometric study. APMIS 1999;107:297-302.

14. Lux ML, Rubin BP, Biase TL, Chen CJ, Maclure T, Demetri G, et al. KIT extracellular and kinase domain mutations in gastrointestinal stromal tumors. Am J Pathol 2000;156:791-5.

15. Miettinen M, Lasota J. Gastrointestinal stromal tumorsdefinition, clinical, histological, immunohistochemical, and molecular genetic features and differential diagnosis. Virchows Arch 2001;438:1-12.

16. Broudy VC, Smith FO, Lin N, Zsebo KM, Egrie J, Bernstein ID. Blasts from patients with acute myelogenous leukemia express functional receptors for stem cell factor. Blood 1992; 80:60-7.

17. Cole SR, Aylett GW, Harvey NL, Cambareri AC, Ashman LK. Increased expression of c-Kit or its ligand Steel Factor is not a common feature of adult acute myeloid leukaemia. Leukemia 1996;10:288-96.

18. Tajima F, Kawatani T, Ishiga K, Nanba E, Kawasaki H. Serum soluble c-kit receptor and expression of c-kit protein and mRNA in acute myeloid leukemia. Eur J Haematol 1998;60: 289-96.

19. Tonary AM, Macdonald EA, Faught W, Senterman MK, Vanderhyden BC. Lack of expression of c-KIT in ovarian cancers is associated with poor prognosis. Int J Cancer 2000; 89:242-50. 
20. Elmore LW, Domson K, Moore JR, Kornstein M, Burks RT. Expression of c-kit (CD117) in benign and malignant human endometrial epithelium. Arch Pathol Lab Med 2001;125:14651.

21. Hines SJ, Organ C, Kornstein MJ, Krystal GW. Coexpression of the c-kit and stem cell factor genes in breast carcinomas. Cell Growth Differ 1995;6:769-79.

22. Chui X, Egami H, Yamashita J, Kurizaki T, Ohmachi H, Yamamoto S, et al. Immunohistochemical expression of the c-kit proto-oncogene product in human malignant and nonmalignant breast tissues. Br J Cancer 1996;73:1233-6.

23. Miettinen M, Sarlomo-Rikala M, Lasota J. KIT expression in angiosarcomas and fetal endothelial cells: lack of mutations of exon 11 and exon 17 of C-kit. Mod Pathol 2000;13:536-41.

24. Ellis GL, Anclair PL. Tumors of the salivary glands. Washington, D.C.: Armed Forces Institute of Pathology; 1996.

25. Vrielinck LJ, Ostyn F, van Damme B, van den Bogaert W, Fossion E. The significance of perineural spread in adenoid cystic carcinoma of the major and minor salivary glands. Int J Oral Maxillofac Surg 1988;17:190-3.

26. Luna MA, el-Naggar A, Batsakis JG, Weber RS, Garnsey LA, Goepfert H. Flow cytometric DNA content of adenoid cystic carcinoma of submandibular gland. Correlation of histologic features and prognosis. Arch Otolaryngol Head Neck Surg 1990;116:1291-6.

27. Spiro RH, Huvos AG. Stage means more than grade in adenoid cystic carcinoma. Am J Surg 1992;164:623-8.

28. Ampil FL, Misra RP. Factors influencing survival of patients with adenoid cystic carcinoma of the salivary glands. J Oral Maxillofac Surg 1987;45:1005-10.

29. Cowie VJ, Pointon RC. Adenoid cystic carcinoma of the salivary glands. Clin Radiol 1984;35:331-3.

30. Matsuba HM, Spector GJ, Thawley SE, Simpson JR, Mauney M, Pikul FJ. Adenoid cystic salivary gland carcinoma. A histopathologic review of treatment failure patterns. Cancer 1986;57:519-24.

31. Shingaki S, Saito R, Kawasaki T, Nakajima T. Adenoid cystic carcinoma of the major and minor salivary glands. A clinicopathological study of 17 cases. J Maxillofac Surg 1986;14: 53-6.

32. Simpson JR, Thawley SE, Matsuba HM. Adenoid cystic salivary gland carcinoma: treatment with irradiation and surgery. Radiology 1984;151:509-12.

33. Matsuba HM, Thawley SE, Simpson JR, Levine LA, Mauney M. Adenoid cystic carcinoma of major and minor salivary gland origin. Laryngoscope 1984;94:1316-8.

34. Holst VA, Marshall CE, Moskaluk CA, Frierson HF, Jr. KIT protein expression and analysis of c-kit gene mutation in adenoid cystic carcinoma. Mod Pathol 1999;12:956-60.

35. Jeng YM, Lin CY, Hsu HC. Expression of the c-kit protein is associated with certain subtypes of salivary gland carcinoma. Cancer Lett 2000;154:107-11.

36. Penner CR, Folpe AL, Budnick SD. C-kit expression distinguishes salivary gland adenoid cystic carcinoma from poly- morphous low-grade adenocarcinoma. Mod Pathol 2002;15: 687-91.

37. Miettinen M. New challenges in the identification of gastrointestinal stromal tumors and other possible KIT-driven tumors. Am J Clin Pathol 2002;117:183-5.

38. Hornick JL, Fletcher CD. Immunohistochemical staining for KIT (CD117) in soft tissue sarcomas is very limited in distribution. Am J Clin Pathol 2002;117:188-93.

39. Miettinen M. Are desmoid tumors kit positive? Am J Surg Pathol 2001;25:549-50.

40. Batsakis JG, Luna MA, el-Naggar A. Histopathologic grading of salivary gland neoplasms: III. Adenoid cystic carcinomas. Ann Otol Rhinol Laryngol 1990;99:1007-9.

41. Greiner TC, Robinson RA, Maves MD. Adenoid cystic carcinoma. A clinicopathologic study with flow cytometric analysis. Am J Clin Pathol 1989;92:711-20.

42. Hamper K, Lazar F, Dietel M, Caselitz J, Berger J, Arps H, et al. Prognostic factors for adenoid cystic carcinoma of the head and neck: a retrospective evaluation of 96 cases. J Oral Pathol Med 1990;19:101-7.

43. Nascimento AG, Amaral AL, Prado LA, Kligerman J, Silveira TR. Adenoid cystic carcinoma of salivary glands. A study of 61 cases with clinicopathologic correlation. Cancer 1986;57: 312-9.

44. Santucci M, Bondi R. Histologic-prognostic correlations in adenoid cystic carcinoma of major and minor salivary glands of the oral cavity. Tumori 1986;72:293-300.

45. Szanto PA, Luna MA, Tortoledo ME, White RA. Histologic grading of adenoid cystic carcinoma of the salivary glands. Cancer 1984;54:1062-9.

46. DiPaola RS, Kuczynski WI, Onodera K, Ratajczak MZ, Hijiya $\mathrm{N}$, Moore J, et al. Evidence for a functional kit receptor in melanoma, breast, and lung carcinoma cells. Cancer Gene Ther 1997;4:176-82.

47. Cohen PS, Chan JP, Lipkunskaya M, Biedler JL, Seeger RC. Expression of stem cell factor and c-kit in human neuroblastoma. The Children's Cancer Group. Blood 1994;84: 3465-72.

48. Timeus F, Crescenzio N, Valle P, Pistamiglio P, Piglione M, Garelli E, et al. Stem cell factor suppresses apoptosis in neuroblastoma cell lines. Exp Hematol 1997;25:1253-60.

49. Parrott JA, Kim G, Skinner MK. Expression and action of kit ligand/stem cell factor in normal human and bovine ovarian surface epithelium and ovarian cancer. Biol Reprod 2000;62: $1600-9$.

50. Ricotti E, Fagioli F, Garelli E, Linari C, Crescenzio N, Horenstein AL, et al. c-kit is expressed in soft tissue sarcoma of neuroectodermic origin and its ligand prevents apoptosis of neoplastic cells. Blood 1998;91:2397-405.

51. Oliveira AM, Hornick JL, Duensing A, Medeiros F, Fletcher CDM, Fletcher JA. KIT expression and activation in adenoid cystic carcinoma [abstract]. Mod Pathol 2003;16:221A. 